\title{
Business Digitalization in Albania: Where do SMEs Stand?
}

\author{
Erjon Curraj
}

PhD Cand. European University of Tirana ${ }^{1}$

\begin{abstract}
The ICTs sector in Albania has marked some considerable progress with the market liberalization, the expansion of the Internet use, the improvements in e-government services and in the policy framework (EC, Progress Report 2012; NSDI, Draft, 2014-2020). The ICTs companies operate mainly at the domestic level, but there are growing efforts to gain better recognition at the regional and international level. The ICTs companies operating in Tirana are mainly registered as SMEs and work in the local market. This paper explores the level of smart business in the ICTs sector in Albania by looking in particular at the current level, future trends and underpinning reasons for the smart business development. The paper provides a framework analysis for smart business as outlined in the survey of literature and explores its contextualization in the ICT sector in Albania by looking at the readiness of the sector to develop smart business. The paper adopts a quantitative methodology and uses both primary and secondary data. The primary data are collected through online structured survey of the ICTs sector in Albania and the secondary data include reports, articles and studies on the ICTs market in Albania.
\end{abstract}

Keywords: ICTs, business, smart business, readiness, process management

\section{Introduction}

When considering the adoption of novel technology in the area of information and communications technologies (ICT), SMEs are often viewed as laggards when viewed against their larger counterparts (OECD, 2004). This is often explained by ignorance, uncertainty and associated risk, coupled with a lack of resource availability, applicability and fewer incentives (Culkin and Smith, 2000; Chanvarasuth, 2010). Of the diverse ICTs forms, Business Intelligence (BI) is acknowledged as a driving force for much development and innovation around the world (UNESCO, 2002;). Larger organizations tend to have a number of suitable characteristics, which lend themselves to effectively adopting $\mathrm{BI}$, such as the necessary level of organizational complexity, the required level and format of data needed for $\mathrm{BI}$ and the necessary budget to support $\mathrm{BI}$. While the majority of emphasis identified in literature (as will be analyzed below) is on the larger companies, the literature relating the use of Business Intelligence and Knowledge Management systems in SMEs is beginning to gradually expand. Although, it can be generally observed that SMEs tend to hesitate in adopting BI due to perceived costs on time, further research is needed to explore the topic. This paper provides a framework analysis for smart business as outlined in the survey of literature and explores its contextualization in the ICT sector in Albania by looking at the readiness of the sector to develop smart business. The paper adopts a quantitative methodology and uses both primary and secondary data. The primary data are collected through online structured survey of the ICTs sector in Albania and the secondary data include reports, articles and studies on the ICTs market in Albania.

\section{Methodology approach}

The following section presents the research context for the study, the research objectives and hypotheses, followed by the theoretical framework and research model and finally the presentation of the data collection strategy and respondent rates and profiles. This study addresses the gaps in our understanding of $\mathrm{BI}$ and its application to SMEs from the perspective of data. In order to understand the impact of BI on SMEs performance in ICT sector, it is important to observe firm characteristics.

\footnotetext{
${ }_{1}^{1}$ Author is a Visiting Researcher at the Lappeenranta University of Technology (LUT), Finland within an Erasmus Mundus Sigma Agile Programme.
} 
Figure 1: Variables and hypothesis

\begin{tabular}{|l|l|}
\hline Variables & Hypothesis \\
\hline Business digitalisation - Business & H1: Business digitalization will impact positively the overall performance of SMEs in \\
Performance & Albania. \\
\hline
\end{tabular}

Figure 2: Variables measurement

\begin{tabular}{|l|l|l|}
\hline Variables & Indicators & Dependent/independent \\
\hline Business Performance of SMEs & $\begin{array}{l}\text { Growth } \\
\text { turnover, employment, profits }\end{array}$ & Dependent \\
\hline Business Digitalisation of SMEs & $\begin{array}{l}\text { Query and reporting tools } \\
\text { Enabled by Business Intelligence }\end{array}$ & Independent \\
\hline
\end{tabular}

An online survey was deemed the most suitable method for achieving the objectives of the study and was developed through the use of an online survey application. The questionnaire is composed of structured and closed questions. Sampling strategy is that of random stratified sampling out of a compiled list of 268 SMEs in Albania. In total, 268 companies were contacted between November 2015 and February 2016 via email or directly through their company contact page on their website where no email address was available or in person via business connection and network. A personalized email was devised and the link to the survey was incorporated and sent to each company individually. A structured threephased follow up strategy was applied. The final sample was 67 SMEs. This paper presents the results only for the ICT sector. The survey respondents were CEO and Founders level, senior management, IT management and others.

\section{Theoretical framework}

Due to the complexities of making effective and timely business decisions in highly competitive markets, Data-driven decision-making using Business Intelligence (BI) applications have attracted many organizations worldwide. However, despite these applications being suited for use in most organizations regardless of size, only the larger enterprises have reached a stage of maturity in BI use while small and medium-size enterprises (SMEs) still lag behind. Whilst many academic researchers have conducted $\mathrm{BI}$ research focused on large organizations, literature relating to $\mathrm{BI}$ adoption within SMEs has remained limited (Boonsiritomachai, et. al, 2014: p. 2). To fill this research gap and support the adoption rate of $\mathrm{BI}$ in SMEs, this paper proposes a research framework for identifying the current state of $\mathrm{BI}$ adoption by SMEs and the enabling factors that impact BI adoption in SMEs. Future research directions for using this framework are also discussed. Gartner Research (2013) found that BI technology is often a first priority in technology investments. This finding agrees with O'Brien and Kok (2006) and Kimball et al. (2008) who found that BI technology had reached a stage of maturity that is widely used at all levels of the business world. Recently, the International Data Corporation (IDC, 2013) reported that the Business Intelligence market had grown by $8.7 \%$ in 2012 , while the total software market and total Information Communication Technology (ICT) market had grown by only $2.9 \%$ and $3.6 \%$, respectively. However, despite BI technology being normally considered as reserved for larger firms, the current demand for $\mathrm{BI}$ is not restricted to firm size (Pegasus Software, 2008). Indeed, both small and medium-sized enterprises now have as much need for BI utilisation as the larger companies (LogicXML, 2009). The accepted classifications of SMEs differ, not only from industry to industry but also from country to country (Atkins and Lowe, 1997), depending on the political and economic objectives defining those (Simpson et al., 2004).

$\mathrm{BI}$ is a systematic process, by which knowledge needed for an organization to compete effectively, is created, captured, shared and leveraged (Foo et al., 2007). The source of such knowledge may be internal or external, individual or collective, historical or forecasted. BI hence consists of a dynamic and continuous set of processes and practices embedded in individuals, as well as in groups and organizational structures. At any point in time, any part of a given organization may be engaged in several different aspects of $B I$ that attempts to constitute a 3608 view of its business health status (Sharma, and Djiaw, 2012: p.114). According to Alavi and Leidner (2001), it is not the quantity of knowledge capital that is a strategic advantage but the organization's ability to effectively apply the existing knowledge to create new knowledge. There are many studies that support BI initiatives and their contribution in aligning organizational goals with objectives. One of them is from report based on a survey of 423 organizations from Europe and the USA (KPMG, 2000). 
Lack of resources is one of the key characteristics many researchers address when studying SMEs. These limited resources include finance, technology, knowledge and human resources. In particular, Bhaird and Lucey (2010) found that financial resources are personally funded by the owner in most SMEs. Due to their restricted financial budgets and low number of employees in SMEs, the majority of employees perform multiple tasks which do not specialise in any particular area (Kirchmer, 2011, Hudson et al., 2001). Moreover, the unskilled workforce with lack of technical specialisation results in SME managers being conservative when adopting IT innovations (Karkoviata, 2001). This may be the reason why many SMEs are reluctant to invest in new technologies and overly careful in assessing any investment strategies involving IT (Nguyen, 2009). For instance, Fuller-Love (2006) found that owner-managers in SMEs deal with IT adoption only when they perceive the promise of success, because they do not want to take risks. This is especially the case for $\mathrm{BI}$, since $\mathrm{BI}$ maintenance and implementation costs are very high as is the failure rate of implementation when compared to other technologies (Lawton, 2006). Also, Hill and Scott (2004) conducted in-depth discussions with eleven SMEs located in Northern Ireland to find that BI technologies are not widely implemented in SMEs because they depend on personal contact networks as a fundamental way of doing business, and are unable to rationalise $\mathrm{BI}$ investments for financial benefits. Moreover, due to their limitations in both human and financial resources and scale and complexity of operations, SMEs require different $\mathrm{Bl}$ approaches from those adopted by large firms (Barnard, 2010).

The European Commission (2008) claimed that more than $95 \%$ of enterprises fall within the SME group as the main driver of the world's economy. As SMEs employ the majority of workers, they contribute to the economic growth of most countries, and are thus widely recognised as vital to economic development and expansion (Levy and Powell, 2005, Roy and Sander, 2004). As a result, the majority of governments support the growth of SMEs as a priority via the creation of various programs including technical support, training, regulatory provisions and policy interventions (Madrid-Guijarro et al., 2009, Esselaar et al., 2007, Chen, 2006). However, even though governments often support SMEs, most SMEs underestimate the value of IT innovations by limiting them to administrative tasks rather than complex business operations (Festing, 2007). As a result, SMEs have lagged in the $\mathrm{BI}$ uptake despite being an important part of enterprise decision support for over two decades (Wirtschaft et al., 2010). According to technology adoption research in SMEs, a number of researchers have found that the structural characteristics of SMEs are different from those in large enterprises, which explicitly affects their IT usage behaviours (Gutierrez et al., 2009, Struker and Gille, 2008, Buonanno et al., 2005). Man et al. (2002) point out that a small enterprise is not a small version of a large enterprise, but has dissimilarities in terms of structure, policy making procedures, and utilisation of resources. Another study on SMEs by Deros et al. (2006) classifies these dissimilarities in terms of structures, systems and procedures, cultures and behaviours, human resources, and markets and customers.

\section{Smart Business - ICT sector in Albania}

The level of digitalisation of SMEs in Albania is assessed through: the ICT needs at the company, the structure of the ICT support, ICT knowledge, Management reports using ICT and frequency of those reports. Initial results show that $44 \%$ of the SMEs report that they have basic technology needs and only $16 \%$ note that they have advanced technology needs. The analysis shows that $33 \%$ of the companies have a dedicated ICT unit in the company. ICT knowledge at the company differs across SMEs and 35\% no expertise for further digitalisation and advanced use of technology. All companies declare to have management reports and data analysis in place for decision-making purposes - the variety and complexity differs. The majority of the SMEs (56\%) state that management reports are created manually using basic office applications + a simple accounting system in place. Only $7 \%$ of the surveyed SMEs make use of advanced analytics such as Business Intelligence or Decisions Support Systems. Management reports are produced only when there is a particular issue at stake at the company $(52 \%)$. Only $12 \%$ of SMEs state that management reports are produced automatically and periodically. There is a growing tendency of SMEs to develop further the ICT sector. $28 \%$ of surveyed SMEs reporting to have expertise and leadership for the digitalisation of their company in line with the overall strategy.

The vast majority of SMEs in Albania (81\%) are not enabled by Business Intelligence. As such, business digitalization level is low in SMEs in Albania and few SMEs report having BI in place. Also, low level of SMEs use BI and analytics for decision making, including ICTs companies. Instead, simple management reports like spreadsheet are used for reporting. The paper argues that reasons behind the low level of $\mathrm{Bl}$ are the following: no clear return on investment; lack of industry standards and promotion of benefits of BI for SMEs; ease-of-use challenges with complex software; less technically savvy employees; vision of owner-manager and lack of ICT knowledge/competences.

Figure 3: Components of BI used at SMEs 


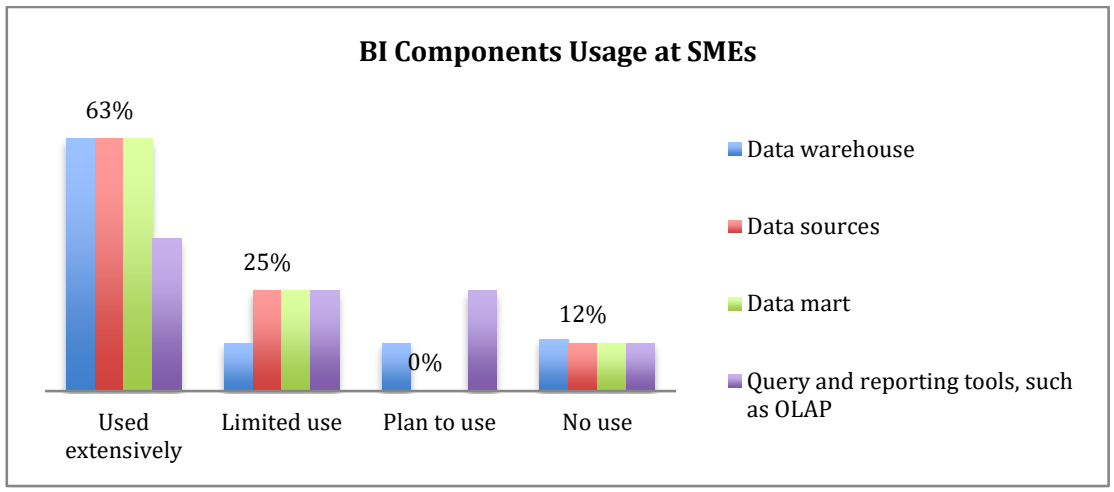

The majority of SMEs, which reported being enabled by $\mathrm{BI}$, state that they use analytics provided by $\mathrm{BI}$ both at the operational and strategic decision making at mid and upper management level. The descriptive statistics shows that the majority of these SMEs use extensively all major components of $\mathrm{Bl}$, namely data warehouse, data sources, data mart and query and reporting tools (63\%). Thus, even within SMEs enabled by BI the extent of advancement in the systems used is relatively limited.

Figure 4: Technology used to share BI insights \& analytics

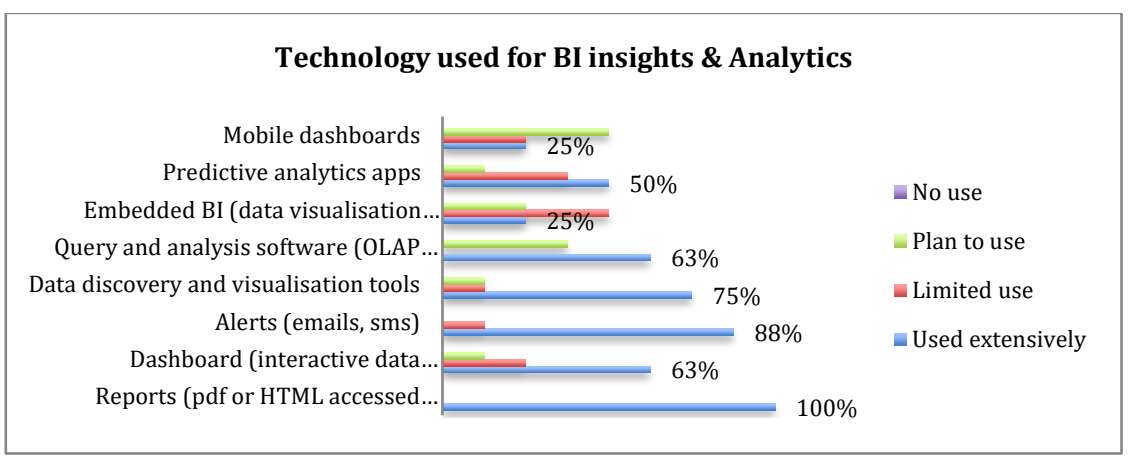

\section{Figure 5: Interest in BI}

\begin{tabular}{|l|l|}
\hline Statement on BI & Level of Agreement \\
\hline $\begin{array}{l}\text { "Higher BI usage in my company offers or will offer greater information } \\
\text { quantity, quality and availability" }\end{array}$ & Strongly agree $-75 \%$ \\
\hline "Helps a company achieve its strategic objectives" & Strongly agree $-62,5 \%$ \\
\hline $\begin{array}{l}\text { "Contributes to the overall effectiveness of a company's decision making } \\
\text { processes" }\end{array}$ & Strongly agree $-62,5 \%$ \\
\hline "Contributes to the overall effectiveness of the whole company" & Strongly Agree $-50 \%$ \\
\hline
\end{tabular}

A growing number of SMEs express an interest in $\mathrm{BI}$ and they state that 'they are exploring opportunities for $\mathrm{BI}$ implementation in their company' (53.2\%). The main reasons for the interest in BI and plans to deploy BI seem to be: Need to save money by reducing costs and/or improving productivity; Need to improve customer satisfaction to remain competitive; Need to improve decision-making, its speed and accuracy.

\section{Conclusions}

The results show that business digitalization impacts positively the overall performance of SMEs in Albania.Size, age and location of the SME dominate performance and are related to the business digitalisation more than strategy. Also the 
entrepreneurial characteristics of the owner - manager also impact the digitalization. Having a clear business plan was also found to be important when it comes to using BI. SMEs in Albania are a vital part of the national economy and from the research it looks that there is growing interest in ICT, digitalisation, $\mathrm{BI}$ and $\mathrm{KM}$, but innovation is still at low levels due to financial and human resources, which are limited. However, it is also seen that SMEs are very flexible and easy to adopt to change and combined this with a visionary owner-manager they tend to move towards business digitalisation. The findings of this research paper have practical implications for the SMEs sector in Albania not only in providing an assessment of the current use of $\mathrm{BI}$, but also in exploring the benefits and potential usage of $\mathrm{BI}$ as a necessary activity for deriving improved performance. The results can provide effective and useful insights for investors and business owners to utilize more appropriate $\mathrm{BI}$ tools and functions to reach more idealistic organizational advantages. Also it enables managers to better understand the application of $\mathrm{Bl}$ functions in the process of achieving the specified managerial support benefits. SMEs can achieve the integration of $\mathrm{BI}$ and $\mathrm{KM}$, which is proven to be a necessity for them in the knowledge economy.

\section{References}

[1] Boonsiritomachai, Waranpong, McGrath, Michael and Burgess, Stephen, (2014). "A research framework for the adoption of Business Intelligence by Small and Medium-sized enterprises", $27^{\text {th }}$ Annual SEAANZ Conference Proceedings, Small Enterprise Association of Australia and New Zealand.

[2] Choudrie, Jyoti and Culkin, Nigel. (2013),"A qualitative study of innovation diffusion: the novel case of a small firm and KTP", Journal of Small Business and Enterprise Development, Vol. 20, No. 4, pp. 889 - 912.

[3] Hawking, Paul and Sellitto, Carmine, (2010). "Business Intelligence (BI) Critical Success Factors", ACIS 2010 Proceedings. Paper 4. Available at http://aisel.aisnet.org/acis2010/4, (accessed in December, 2015).

[4] Ivers, Anne Marie, Byrne, PJ. and Byrne, James, (2016),"Analysis of SME data readiness: a simulation perspective", Journal of Small Business and Enterprise Development, Vol. 23, No. 1, pp. - 1-33.

[5] Olszak, M. Celina, (2013), "Assessment of Business Intelligence Maturity in the Selected Organisations", Proceedings of the 2013 Federated Conference on Computer Science and Information Systems, pp. 951-958.

[6] Ramdani, Boumedien, Chevers, Delroy, and Williams, Densil A. (2013), "SMEs' adoption of enterprise applications", Journal of Small Business and Enterprise Development, Vol. 20, No. 4, pp. 735 - 753.

[7] Sharma, Ravi S., and Djiaw, Vironica, (2011). "Realising the strategic impact of business intelligence tools", The journal of information and knowledge management systems, Vol. 41, No. 2, pp. 113-131.

[8] Theodoridis, Constantinos and Priporas, Constantinos V., (2013). "Strategic Decision-Making during Uncertainty: Implications for SMEs", in Vrontis, Demetris and Thrassou, Alkis, (Eds.), Innovative Business Practices: Prevailing a Turbulent Era, UK: Cambridge Scholars Publishing, pp. 87-112.

[9] World Bank. (2016). World Development Report 2016: Digital Dividends. Washington, DC: World Bank. 